\title{
Catalytic Dehydrogenation of Methylcyclohexane by Pt Nanoparticles Supported on Nitrogen doped Carbon
}

\author{
Jian Wang, Shiguang Fan, Xuan Xu, Huiru Yun, He Liu*, and Zongxian Wang* \\ State Key Laboratory of Heavy Oil Processing, College of Chemical Engineering, China University of Petroleum (East China), Qingdao \\ 266580, China.
}

\begin{abstract}
Pt nanoparticles supported on nitrogen doped carbon $(\mathrm{Pt} / \mathrm{CN})$ catalysts with different surface areas were obtained and characterized by transmission electron microscope (TEM) and brunner-emmetteller (BET). The characterized results showed that Pt nanoparticles dispersed uniformly on the support surface, and the surface area of the Pt/CN catalyst increased with the increase of annealing temperature. Subsequently, the catalytic performance of $\mathrm{Pt} / \mathrm{CN}$ catalysts for methylcyclohexane dehydrogenation was studied. The activity of $\mathrm{Pt} / \mathrm{CN}$ catalysts in methylcyclohexane dehydrogenation increased with the increase of the surface area, $\mathrm{Pt} / \mathrm{CN}-1000$ catalyst has the largest surface area and the highest catalytic activity, with the methylcyclohexane conversion of $99 \%$ and the TOF value of $424.78 \mathrm{~h}^{-1}$ at $180{ }^{\circ} \mathrm{C}$ for 150 minutes.
\end{abstract}

\section{Introduction}

As a renewable clean energy, hydrogen energy is gradually applied to replace the traditional fossil energy. However, hydrogen is easy to leak, flammable and explosive under normal temperature and pressure, which makes it difficult for large-scale storage and longdistance transportation. A series of hydrogen storage materials, such as MOFs, metal hydride, organic liquid hydrogen storage materials, are utilized to store hydrogen and solve the problem [1,2]. Organic liquid hydrogen storage materials can store and release hydrogen through hydrogenation and dehydrogenation process. They have attracted the attention because of the large amount of hydrogen storage, safe and cheap. The commonly used organic hydrides are cyclohexane, methylcyclohexane, decalin, etc. However, the dehydrogenation temperature of the organic liquid hydrogen storage materials is high (around $300{ }^{\circ} \mathrm{C}$ ), which makes the dehydrogenation products further dehydrogenation and carbonization on the catalyst surface, resulting in catalyst deactivation and hydrogen impurity [3-5]. Therefore, it is very important to develop a low temperature and high efficiency catalyst for organic liquid dehydrogenation.

Noble metals (such as $\mathrm{Pt}, \mathrm{Pd}, \mathrm{Rh}$, Ir) have been employed as organic liquid dehydrogenation catalysts [612]. Pt is favoured by researchers for its excellent stability and oxidation resistance. In order to improve the activity of catalysts, Pt based bimetallic catalysts have been reported. Another strategy to improve catalytic activity is using carbon-based materials as the supports. The surface can be modified with functional groups which can change the dispersion of active components and surface electronic structure. Nitrogen doped carbon support is one of the most widely used carbon-based supports. Nitrogen doped carbon support not only has the advantages of traditional carbon materials, $\mathrm{N}$ species on the surface of nitrogen doped carbon support can anchor the active component, improve the surface electronic structure of the active component and enhance the catalytic activity.

In this paper, a series of nitrogen doped carbon supported $\mathrm{Pt}$ catalysts were synthesized for the dehydrogenation of methylcyclohexane. The physical and chemical properties of the catalyst were characterized by BET and TEM. The study on the dehydrogenation of methylcyclohexane showed that the larger specific surface area of the catalyst, the better dehydrogenation performance of methylcyclohexane. $\mathrm{Pt} / \mathrm{CN}-1000$ exhibited the best catalytic activity which was four times of commercial Pt/C (TOF value).

\section{Experimental}

\subsection{Materials}

Methylcyclohexane $\left(\mathrm{CH}_{3} \mathrm{C}_{6} \mathrm{H}_{6}\right)$, glucose $\left(\mathrm{C}_{6} \mathrm{H}_{12} \mathrm{O}_{6}\right)$, dicyandiamide $\left(\mathrm{C}_{2} \mathrm{H}_{4} \mathrm{~N}_{4}\right)$, chloroplatinic acid hexahydrate $\left(\mathrm{H}_{2} \mathrm{PtCl}_{6} \cdot 6 \mathrm{H}_{2} \mathrm{O}\right)$, sodium borohydride $\left(\mathrm{NaBH}_{4}\right)$, sodium hydroxide $(\mathrm{NaOH})$, ethanol $\left(\mathrm{CH}_{3} \mathrm{CH}_{2} \mathrm{OH}\right)$ and $\mathrm{Pt} / \mathrm{C}$ were purchased from Shanghai Chemical Reagent Company. $\mathrm{SiO}_{2}$ colloidal was purchased from Aldrich. All reagents were used as received and without any other purification.

\subsection{Catalysts Preparation}

\footnotetext{
* Corresponding author: Liu: aoyun3002008@126.com, Wang: heavyoil@upc.edu.cn
} 
Synthesis of Nitrogen doped Carbon Support (CN). In a typical experiment, a mixture of dicyandiamide $(2 \mathrm{~g})$, glucose $(2 \mathrm{~g})$ and $\mathrm{SiO}_{2}$ colloidal $(8 \mathrm{~g})$ in $\mathrm{H}_{2} \mathrm{O}(40 \mathrm{~mL})$ was added to $150 \mathrm{~mL}$ round-bottom flask and evaporated at $120{ }^{\circ} \mathrm{C}$. The products were annealed in a tubular furnace at $700-1000{ }^{\circ} \mathrm{C}$ for 3 hours under Ar atmosphere. After centrifugation, washing to neutral and drying, nitrogen doped carbon support $(\mathrm{CN})$ was obtained.

Synthesis of Pt/CN Catalysts. $\mathrm{H}_{2} \mathrm{O}(40 \mathrm{~mL})$ was added in $100 \mathrm{~mL}$ round-bottom flask, and then $\mathrm{CN}$ support $(400 \mathrm{mg})$ and $\mathrm{H}_{2} \mathrm{PtCl}_{6} \cdot 6 \mathrm{H}_{2} \mathrm{O}(640 \mu \mathrm{L} 0.1 \mathrm{~g} / \mathrm{mL})$ were added. After stirring for 24 hours at room temperature, the dispersion was reduced by $\mathrm{NaBH}_{4}$. After centrifugation, washing and drying, the catalysts were obtained and labelled as $\mathrm{Pt} / \mathrm{CN}-\mathrm{x}$ (where $\mathrm{x}$ represents the annealing temperature).

\subsection{Catalysts Characterizations}

The morphologies of catalysts were performed on transmission electron microscope (TEM, JEM2100UHR). The surface area and pore size of catalysts were determined at Micromeritics ASAP 2020 instrument by $\mathrm{N}_{2}$ adsorption/desorption isotherm.

\subsection{Catalytic Dehydrogenation Methylcyclohexane}

of

Catalyst $(120 \mathrm{mg})$ and methylcyclohexane $(420 \mu \mathrm{L})$ were sealed into the reaction tube, and the air in the reaction tube was replaced by argon. Subsequently, the reaction tube was heated to $180{ }^{\circ} \mathrm{C}$ (the temperature of catalyst surface) for the dehydrogenation reaction.

\section{Results and Discussion}

\subsection{Physicochemical properties of $\mathrm{Pt} / \mathrm{CN}$ catalysts}

The $\mathrm{N}_{2}$ adsorption/desorption isotherms and pore size distribution curves of Pt/CN catalysts were shown in Fig. 1 and the processed data were listed in Table 1. The BET surface areas of $\mathrm{Pt} / \mathrm{CN}-\mathrm{x} \quad(\mathrm{x}=700-1000)$ catalysts increased gradually with the increase of temperature and were mainly distributed in the $595.65-884.86 \mathrm{~m}^{2} \cdot \mathrm{g}^{-1}$. However, there were no significant difference in the pore size of the catalysts. As shown in Fig. 1(b), the pore sizes were mainly distributed in the $10.1-10.7 \mathrm{~nm}$.

In order to better understand the catalytic performance of the $\mathrm{Pt} / \mathrm{CN}-\mathrm{x}(\mathrm{x}=700-1000)$ catalysts, the catalysts were tested by ICP-AES, and the detailed data are shown in Table 1. The Pt loading of $\mathrm{Pt} / \mathrm{CN}-\mathrm{x}$ $(x=700-1000)$ catalysts were $2.35 \mathrm{wt} \%, 2.63 \mathrm{wt} \%, 2.95$ $\mathrm{wt} \%, 3.34 \mathrm{wt} \%$, respectively. The results show that with the increase of surface area, the amount of Pt adsorbed on the support surface increases gradually. The results revealed that all $\mathrm{Pt} / \mathrm{CN}$ catalysts have homogeneous mesoporous structure and $\mathrm{Pt} / \mathrm{CN}-1000$ catalyst has the highest surface area and the highest Pt loading amount.

\begin{tabular}{|c|c|c|c|}
\hline Sample & $\mathrm{Pt}(\mathrm{wt} \%)$ & $\mathrm{S}_{\text {BET }}\left(\mathrm{m}^{2} / \mathrm{g}\right)$ & $\mathrm{d}_{\mathrm{BJH}}(\mathrm{nm})$ \\
\hline $\mathrm{Pt} / \mathrm{CN}-700$ & 2.35 & 595.65 & 10.1. \\
\hline $\mathrm{Pt} / \mathrm{CN}-800$ & 2.63 & 699.53 & 10.7 \\
\hline $\mathrm{Pt} / \mathrm{CN}-900$ & 2.95 & 762.31 & 10.3 \\
\hline $\mathrm{Pt} / \mathrm{CN}-1000$ & 3.34 & 884.86 & 10.2 \\
\hline
\end{tabular}
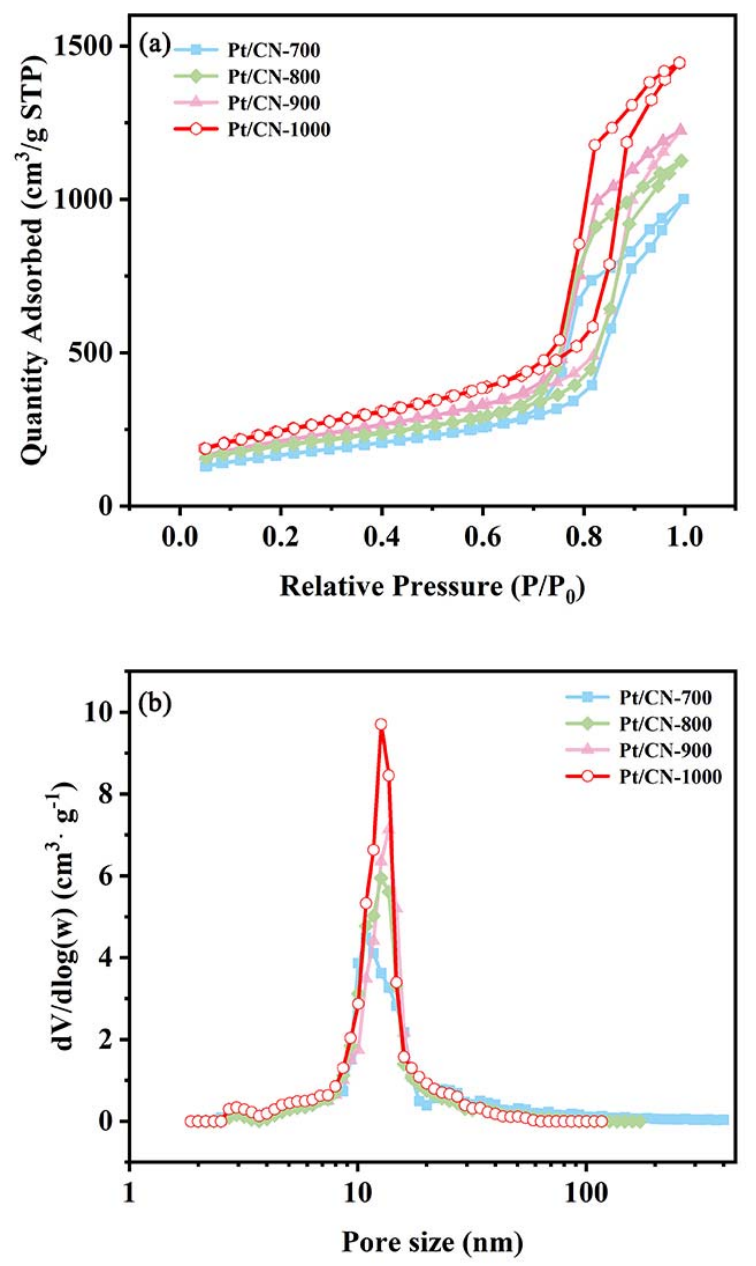

Fig. 1. The $\mathrm{N}_{2}$ adsorption/desorption isotherms and pore size distribution curves of $\mathrm{Pt} / \mathrm{CN}$ catalysts

The TEM photographs and particle size chart of $\mathrm{Pt} / \mathrm{CN}-\mathrm{x}(\mathrm{x}=700-1000)$ catalysts are shown in Fig. 2. It can be seen from Fig. 2 that the surface of the nitrogen doped carbon support are honeycombed structure and $\mathrm{Pt}$ nanoparticles are uniformly distributed on the surface. The size distribution of Pt nanoparticles was obtained by counting 200 particles in TEM images. The size of Pt nanoparticles on the supports with different annealing temperatures was slightly different, and the average $\mathrm{Pt}$ particle size of all $\mathrm{Pt} / \mathrm{CN}$ catalysts was mainly distributed in $2.35-2.76 \mathrm{~nm}$. It is revealed that the size of Pt particles is also affected by the surface area of the catalyst support.

Table 1. Physical parameters sections of $\mathrm{Pt} / \mathrm{CN}$ catalysts 


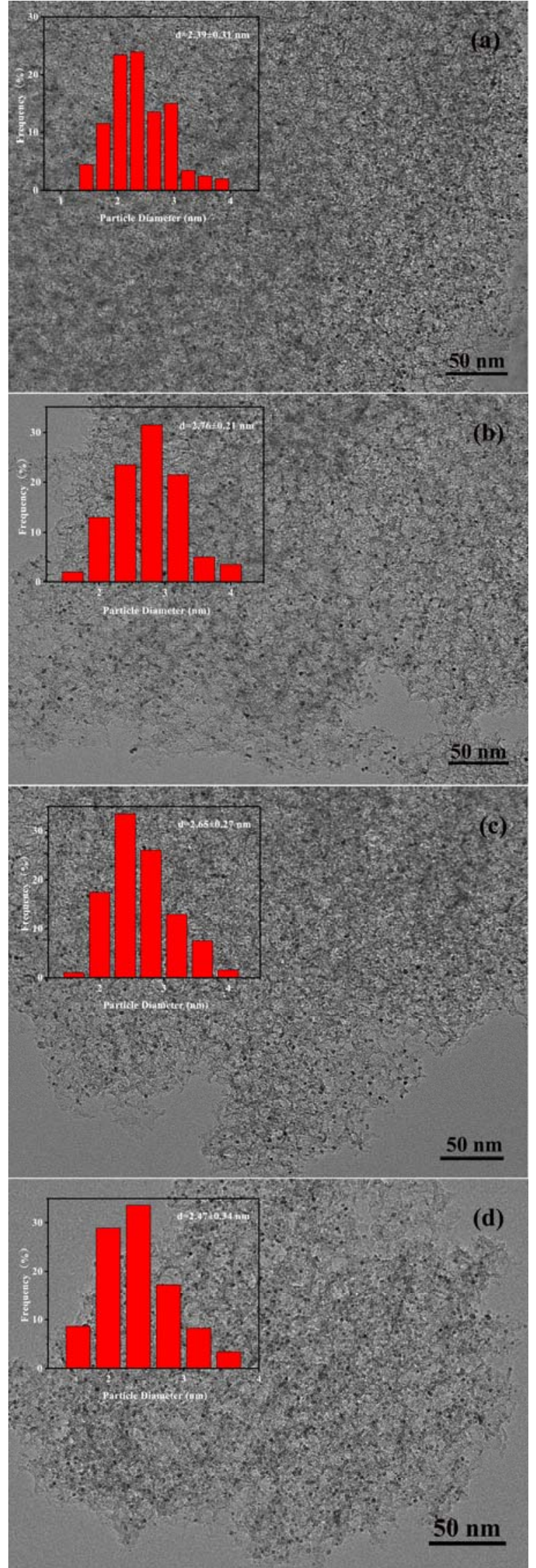

Fig. 2. TEM images of $\mathrm{Pt} / \mathrm{CN}$ catalysts

\subsection{Catalytical activity}
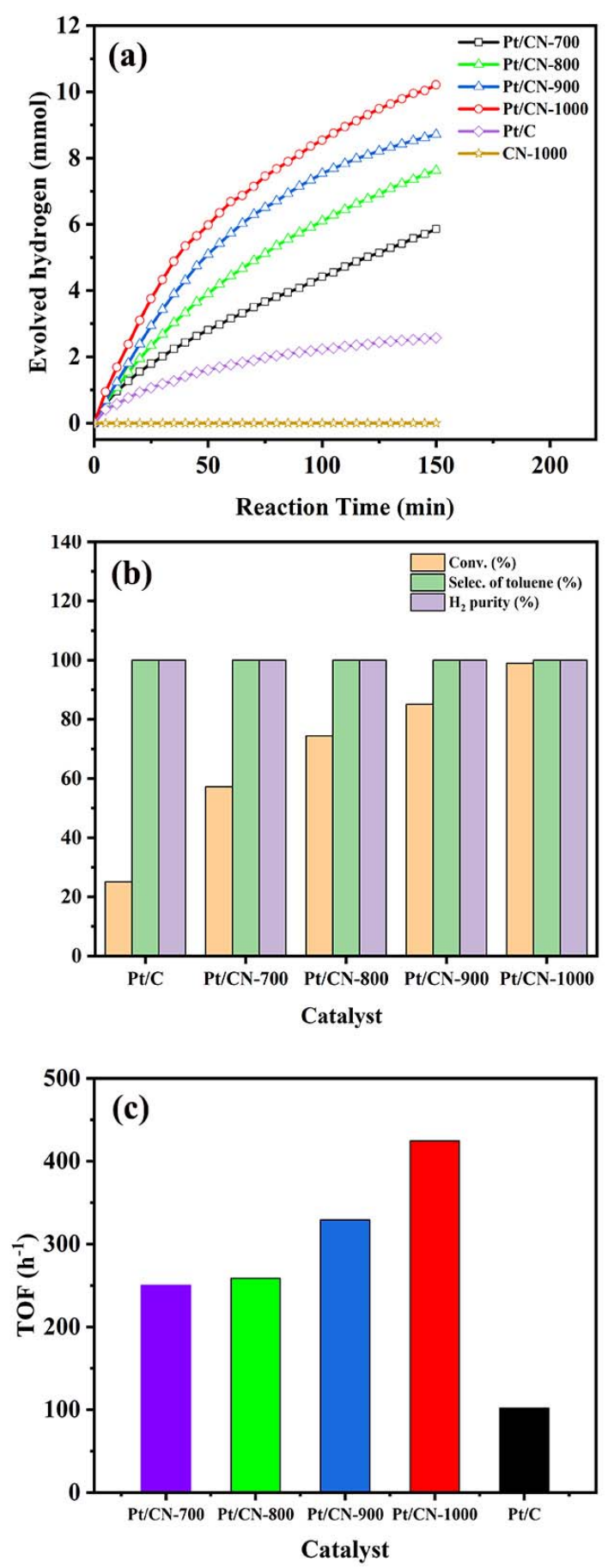

Fig. 3. Catalytic performances of $\mathrm{Pt} / \mathrm{CN}$ catalysts

The catalytic performances of $\mathrm{Pt} / \mathrm{CN}-\mathrm{x}(\mathrm{x}=700-1000)$ catalysts over dehydrogenation of methylcyclohexane were shown in Fig. 3. Compared with commercial Pt/C catalyst, $\mathrm{Pt} / \mathrm{CN}-\mathrm{x}(\mathrm{x}=700-1000)$ catalysts have better performance in dehydrogenation of methylcyclohexane. Among them, Pt/CN-1000 has the highest hydrogen production and conversion, and the conversion reaches $99 \%$. To compare the catalytic activity of the catalysts more clearly, the turnover frequencies (TOF) of the catalysts are shown in Fig. 3(c). With the increase of annealing temperature, the TOF value of $\mathrm{Pt} / \mathrm{CN}-\mathrm{x}$ $(x=700-1000)$ catalysts increase gradually. The TOF value of $\mathrm{Pt} / \mathrm{CN}-1000$ catalyst was $424.78 \mathrm{~h}^{-1}$, which was 
4 times of commercial $\mathrm{Pt} / \mathrm{C}$. It indicated that higher catalytic activity can be obtained with larger specific surface area and $\mathrm{Pt} / \mathrm{CN}-1000$ catalyst exhibited the best catalytic activity in methylcyclohexane dehydrogenation .

\section{Conclusions}

In this work, Pt nanoparticles supported on nitrogendoped carbon catalysts were synthesized. By adjusting the annealing temperature of the support, mesoporous $\mathrm{Pt} / \mathrm{CN}$ catalysts with different surface areas were obtained. It was found that with the increase of annealing temperature, the specific surface area of the catalyst increased gradually, and the catalytic activity for methylcyclohexane dehydrogenation increased gradually. The Pt/CN-1000 catalyst has the highest catalytic activity and the conversion of methylcyclohexane reaches $99 \%$ and the TOF value is $424.78 \mathrm{~h}^{-1}$ at $180^{\circ} \mathrm{C}$.

\section{Acknowledgement}

This work was supported by the National Natural Science Foundation of China (Grant 21908248), the Fundamental Research Funds for the Central Universities (Grant 19CX02013A), the Provincial Natural Science Foundation of Shandong (Grant ZR2017BB021), the Provincial Postdoctoral Research Founding of Shandong (201702028), the State Key Laboratory of Heavy Oil Processing (SLKZZ-2017003).

\section{References}

1. L. Schlapbach, A. Züttel. Nature 414, 353 (2001).

2. J. Andersson, S. Grönkvist. Int. J. Hydrogen Energ. 44, 11901 (2019).

3. Z. Wang, Z. Cheng, W. Yuan, J. Cai, L. Zhang, F. Zhang, et al. Combust. Flame 159, 2243 (2012).

4. B.E. Koel, D.A Blank., E.A. Carter. J. Mol. Catal. A-Chem. 131, 39 (1998).

5. A.A Shukla., P.V. Gosavi, J.V. Pande, V.P. Kumar, K.V.R. Chary, R.B. Biniwale. Int. J. Hydrogen Energ. 35, 4020 (2010).

6. N. Kariya, A. Fukuoka, T. Utagawa, M. Sakuramoto, Y. Goto, M. Ichikawa. Appl. Catal. A: Gen. 247, 247 (2003).

7. J. Yu, R. Wang, S. Ren, X. Sun, C. Chen, Q. Ge, et al. ChemCatChem 4, 1376 (2012).

8. Laila I. Alia A-GAA., S.M. Aboul-Fotouha, Ahmed K. Aboul-Gheit. Appl. Catal. A: Gen. 177, 99 (1999).

9. B-H. Jeong, K-I. Sotowa, K. Kusakabe. J. Membrane Sci. 224, 151 (2003).

10. A.F. Nobuko Kariya, Masaru Ichikawa. Appl. Catal. A: Gen. 233, 91 (2002).

11. R.B. Biniwale, H. Yamashiro, M. Ichikawa. Catal. Lett. 102, 23 (2005).
12. N.S. Yuguo Wang, P. Gerald Huffman. Energ. Fuel. 18, 1429 (2004). 